\title{
RELAÇÕES ENTRE TAMANHO DE SEDIMENTOS ERODIDOS, VELOCIDADE DA ENXURRADA, RUGOSIDADE SUPERFICIAL CRIADA PELO PREPARO E TAMANHO DE AGREGADOS EM SOLO SUBMETIDO A DIFERENTES MANEJOS ${ }^{(1)}$
}

\author{
Leandro Bochi da Silva Volk ${ }^{(2)} \&$ Neroli Pedro Cogo ${ }^{(3)}$
}

\begin{abstract}
RESUMO
Vários fatores determinam a seletividade do processo de erosão hídrica pluvial no que se refere ao tamanho dos sedimentos transportados na enxurrada. Dentre eles, destacam-se a intensidade da chuva e da enxurrada a ela associada, a textura e o grau de consolidação da camada superficial do solo, a forma em que a erosão ocorre (entre sulcos, sulco ou voçoroca), a cobertura do solo por resíduos culturais, o microrrelevo do terreno ou a rugosidade superficial resultante do seu preparo e o tamanho e a estabilidade dos agregados do solo. Considerando isso, realizou-se este trabalho com o propósito de estabelecer relações quantitativas entre o índice $D_{50}$ da distribuição de tamanho dos sedimentos erodidos, a velocidade da enxurrada, o índice IR da rugosidade superficial do solo criada pelo preparo e o diâmetro médio ponderado (DMP) dos agregados do solo, em solo submetido a diferentes formas de manejo. $O$ estudo foi desenvolvido em campo, na Estação Experimental Agronômica da Universidade Federal do Rio Grande do Sul (EEA/UFRGS), em Eldorado do Sul (RS), aplicando-se chuva simulada sobre um Argissolo Vermelho com textura francoargiloarenosa na camada superficial e declividade média de $0,115 \mathrm{~m} \mathrm{~m}^{-1}$. Esse solo havia sido submetido ao uso agrícola de diferentes modos (cultivos contínuo e interrompido), com diferentes sequências culturais (gramíneas e leguminosas de inverno e verão, implantadas em fileira, usando a técnica de semeadura direta), durante 7,5 anos (partindo da condição original de campo nativo). Efetuaram-se sete testes de erosão na pesquisa, cada um deles na intensidade constante de chuva de $63,5 \mathrm{~mm} \mathrm{~h}^{-1}$ e com duração de $1,5 \mathrm{~h}$, usando o simulador de chuva de braços rotativos e parcelas experimentais com dimensões de 3,5 x 11,0 m cada uma. Os referidos testes de erosão foram realizados nas
\end{abstract}

\footnotetext{
(1) Parte da Tese de Doutorado do primeiro autor apresentada no PPG Ciência do Solo, Universidade Federal do Rio Grande do Sul - UFRGS. Trabalho apresentado na XVI Reunião Brasileira de Manejo e Conservação do Solo e da Água, Aracajú (SE) 2006, e realizada com recursos financeiros do Projeto CNPq-PRONEX/Solos e Auxílio "grant"/CNPq, e com o apoio de bolsistas de iniciação científica dos Programas PIBIC/CNPq-UFRGS, CNPq e FAPERGS. Recebido para publicação em outubro de 2008 e aprovado em agosto de 2009.

(2) Professor Adjunto, Departamento de Agronomia, Campus Regional de Umuarama, UEM. Ex-bolsista CAPES. E-mail: lbsvolk@uem.br

(3) Professor Associado, Departamento de Solos, Faculdade de Agronomia, Universidade Federal do Rio Grande do Sul - UFRGS. Av. Bento Gonçalves 7712, CEP 91540-000 Porto Alegre (RS). Bolsista do CNPq. E-mail: neroli@ufrgs.br
} 
seguintes condições físicas de superfície do solo: (a) solo não-mobilizado, com completa e nenhuma cobertura por resíduos culturais, e (b) solo sucessivamente mobilizado com grade leve de discos (cinco vezes, uma gradagem por vez), com nenhuma cobertura. As sequências culturais proporcionaram valores de DMP significativamente diferentes entre si, o que se refletiu em valores significativamente diferentes do índice IR e, em consequência, da velocidade da enxurrada e do índice $D_{50}$, com as sequências com nenhum ou menos tempo de supressão do cultivo (no último período da pesquisa) tendo produzido os melhores resultados. No solo não-mobilizado e totalmente coberto, com a superfície consolidada e praticamente nenhuma rugosidade, a cobertura por resíduos culturais foi o fator determinante, tanto da redução da velocidade da enxurrada, quanto do aprisionamento das eventuais partículas desagregadas de solo de maior tamanho, o que acarretou valores do índice $D_{50}$ muito pequenos. No solo nãomobilizado e descoberto, em que a enxurrada atingiu as suas maiores velocidades, o tamanho dos sedimentos erodidos foi ditado pela consolidação da superfície do solo e pelos valores do índice DMP, sendo os menores para os maiores valores das duas últimas variáveis referidas. Já no solo sucessivamente mobilizado com grade leve e descoberto, com a superfície solta e rugosa, a rugosidade superficial criada pelo preparo foi o fator determinante, tanto da redução da velocidade da enxurrada, quanto do aprisionamento das partículas desagregadas de solo de maior tamanho, o que aumentou o percentual das partículas erodidas com tamanho $<0,0375 \mathrm{~mm}$ e, em decorrência, diminuiu os valores do índice $\mathrm{D}_{50}$, independentemente dos valores de DMP. O aumento dos valores de DMP acarretou maior valor e maior persistência da rugosidade superficial do solo criada pelo preparo e, como consequência, diminuiu de modo mais efetivo a velocidade da enxurrada e o tamanho dos sedimentos erodidos. As relações matemáticas efetuadas com as variáveis em consideração indicaram tendência de ajustes significativos a modelos linear e nãolinear e foram coerentes na descrição dos processos que se pretendia visualizar com a realização da pesquisa.

Termos de indexação: chuva simulada, preparo do solo, sistemas de cultivo, resíduos culturais, índice DMP, índice $\mathrm{D}_{50}$

\section{SUMMARY: RELATIONSHIPS BETWEEN SIZE OF ERODED SEDIMENTS, RUNOFF VELOCITY, SURFACE ROUGHNESS CREATED BY TILLAGE, AND SIZE OF AGGREGATES IN A SOIL SUBMMITED TO DIFFERENT MANAGEMENTS}

\footnotetext{
Several factors determine the selectivity of the soil erosion process by rainfall concerning the size of eroded-sediments transported in the runoff water. Among them, it is important to point out the intensity of the rainfall and its associated runoff, the texture and degree of consolidation of the soil surface layer, the form of erosion (interill, rill, or gully), the microrelief of the terrain or surface roughness created by tillage, and the size and stability of the soil aggregates. Considering that, this work was accomplished with the purpose of establishing quantitative relationships between the $D_{50}$ index of the size distribution of the soil-eroded sediments, the runoff velocity, the SR index of the tillage-induced soil surface roughness, and the mean weight diameter (MWD) of the soil aggregates, in a soil submitted to different forms of management. The study was developed in the field, at the Agricultural Experimentation Station of the Federal University of Rio Grande do Sul (EEA/UFRGS), in Eldorado do Sul (RS), Brazil, by applying simulated rainfall on an Ultisol with a sandy clay loam texture in the surface layer and $0.115 \mathrm{~m} \mathrm{~m}^{-1}$ average slope steepness. This soil had been put into agricultural use by different manners (continuous and discontinued cultivation), with different crop sequences (winter and summer, grass and legume crop species, planted in rows, using notillage), for a 7.5 year period (starting at the original condition of native pasture). Seven erosion tests were performed in the study, each one of them at $63.5 \mathrm{~mm} \mathrm{~h}^{-1}$ rainfall intensity and $1.5 \mathrm{~h}$ duration, using the rotating-boom rainfall simulator and $3.5 \times 11.0 \mathrm{~m}$ experimental plots. The referred erosion tests were performed in the following soil surface physical conditions: (a) non-mobilized soil, with complete and no cover by crop residues, and (b) soil successively mobilized by the passage of a light disc-harrow (five times, one at a time), with no cover. It was observed that the crop sequences provided values of the MWD index significantly different each
} 


\begin{abstract}
other, which reflected in significantly different values of the SR index and, as consequence, of the runoff velocity and the $D_{50}$ index, with the sequences with none or less time of discontinued cultivation (in the last period of the research) having produced the best results. In the nonmobilized, completely mulch-covered soil, with a firm and smooth surface, the mulch of crop residues was the dominant factor either in reducing the runoff velocity or in trapping the eventually detached soil particles of larger size, which led to very small values of the $D_{50}$ index. In the non-mobilized, uncovered soil, where runoff reached its highest velocities, the size of the eroded sediments was determined by the consolidation of the soil surface and by the values of the MWD index, being the smaller for the greater values of the two last variables mentioned. Yet in the soil successively mobilized by the one at a time passage of a light disc-harrow and bare, with a loose and rough surface, the roughness of the soil surface created by tillage was the dominant factor either in reducing the runoff velocity or in trapping the detached soil particles of larger size, which increased the percentage of eroded sediments $<0.0375 \mathrm{~mm}$ and, as a consequence, decreased the values of the $D_{50}$ index, regardless of the values of the MWD index. The increase in the mean-weight-diameter (MWD) of the soil aggregates provided higher values and higher persistence of the tillage-induce soil surface roughness, which reflected in a more effective decrease of the runoff velocity and the size of the soil-eroded sediments. The mathematical relationships performed with the variables under consideration indicated a tendency for significant adjustments to linear and non-linear models and were coherent in describing the processes intended to be visualized with the accomplishment of the research.
\end{abstract}

\title{
Index terms: simulated rainfall, soil tillage, cropping system, crop residues, $M W D$ index, $D_{50}$ index.
}

\section{INTRODUÇÃO}

O conhecimento da distribuição do tamanho dos sedimentos erodidos tem importância nos assuntos de modelagem relacionada com a perda de solo e de nutrientes, a produção e o transporte de sedimentos, a poluição das fontes superficiais de água e a quantidade de carbono liberada para a atmosfera pelo referido fenômeno. Vários fatores determinam o tamanho dos sedimentos erodidos transportados na enxurrada associada à erosão hídrica pluvial do solo. Dentre eles, destacam-se a intensidade da chuva e do escoamento superficial, a textura do solo e o grau de consolidação da sua superfície, a forma da erosão (entre sulcos, sulco e, ou, voçoroca), a cobertura do solo por resíduos culturais, o microrrelevo do solo ou rugosidade superficial criada pelo preparo e o tamanho e a estabilidade dos agregados do solo (Gilley et al., 1986; Lopes et al., 1987; Mutchler \& Murphree, 1988; Shainberg et al., 1992; Hudson, 1995). Chuvas de grande intensidade causam maior desagregação do solo e, normalmente, originam escoamento superficial com maior capacidade erosiva do que chuvas de pequena intensidade, o que favorece o transporte de sedimentos de tamanho grande na enxurrada (Sidiras et al., 1984). Chuvas de padrão atrasado, cujo pico da intensidade ocorre quando o solo se encontra próximo ou no ponto de saturação, resultam em maior quantidade de sedimentos grandes transportados na enxurrada do que as chuvas de padrões avançado e intermediário. Devido às diferenças nas características hidráulicas, o fluxo laminar (delgado) associado à erosão e entre sulcos tem pouca capacidade de desagregar e de transportar partículas de solo de maior tamanho, enquanto o fluxo canalizado (espesso) associado à erosão em sulcos tem grande capacidade (Shainberg et al., 1992; Hudson, 1995). Solos de textura argilosa, de modo geral, resistem mais à desagregação de suas partículas pela ação dos agentes erosivos do que solos de textura arenosa; contudo, os sedimentos originados dos primeiros são mais facilmente transportados do que os dos últimos (Wischmeier \& Smith, 1978; Hudson, 1995). Rampas longas e declive muito inclinados aumentam o volume e a velocidade da enxurrada, o que aumenta a sua capacidade erosiva para desagregar o solo e transportar as partículas de maior tamanho. A velocidade é o componente de energia cinética que, em maior grau, determina a capacidade erosiva da enxurrada de desagregar e de transportar solo nos terrenos inclinados, exercendo influência direta no tamanho dos sedimentos removidos pela erosão (Lopes et al., 1987; Hudson, 1995). Dentre as condições físicas externas ou superficiais do solo, a cobertura por resíduo cultural e a rugosidade induzida pelas operações de seu preparo são as responsáveis pelas maiores reduções, tanto da quantidade quanto do tamanho dos sedimentos erodidos transportados na enxurrada (Johnson et al., 1979; Cogo et al., 1983, 1984; Norton et al., 1985; Gilley et al., 1986; Lopes et al., 1987). A maior estabilidade dos agregados do solo e sua decorrente maior resistência às forças erosivas também determinam menor quantidade e menor tamanho dos sedimentos transportados na enxurrada (Le Bissonnais \& Arrouyas, 1997; Albuquerque et al., 2000).

Considerando o exposto, este trabalho foi realizado com o objetivo de estabelecer relações quantitativas entre o tamanho dos sedimentos erodidos, a velocidade da enxurrada, a rugosidade superficial do solo criada 
pelo preparo e o tamanho dos agregados do solo, utilizando-se um Argissolo Vermelho distrófico típico submetido a diferentes formas de manejo, chuva simulada e parcelas de erosão com dimensões de $3,5 \times 11,0 \mathrm{~m}$.

\section{MATERIAL E MÉTODOS}

O estudo foi realizado em campo da Estação Experimental Agronômica da Universidade Federal do Rio Grande do Sul (EEA/UFRGS), em Eldorado do Sul (RS), na região fisiográfica da Depressão Central. Segundo a classificação de Köppen, o clima desta região é do tipo "Cfa" - subtropical úmido sem estação seca definida. O solo da área experimental é classificado como Argissolo Vermelho distrófico típico (Streck et al., 1999; Embrapa, 2006), apresentando textura francoargiloarenosa no horizonte $\mathrm{A}$, drenagem moderada, declividade média de $0,115 \mathrm{~m} \mathrm{~m}^{-1} \mathrm{e}$ profundidade efetiva inferior a $0,80 \mathrm{~m}$.

A pesquisa foi realizada com chuva simulada, empregando-se o aparelho simulador do tipo de braços rotativos ou modelo Swanson (Swanson, 1965). Este aparelho asperge água na forma de gotas simultaneamente sobre duas parcelas experimentais ou parcelas de erosão. Neste trabalho, as duas parcelas constituintes de dado par foram usadas como repetições dos tratamentos, resultando em duas para cada um. As parcelas em consideração possuíam 3,5 m de largura por $11 \mathrm{~m}$ de comprimento cada uma, com a maior dimensão disposta no sentido da pendente do terreno, espaçadas uma da outra, num dado par, de 3,5 m, conforme recomendações de Embrapa (1975). Cada parcela foi delimitada nas laterais e na porção superior por chapas galvanizadas com $2 \mathrm{~m}$ de comprimento e $0,2 \mathrm{~m}$ de altura cada uma, as quais foram cravadas $0,1 \mathrm{~m}$ no solo. Na porção inferior de cada parcela, foi instalada uma calha especial para a coleta da enxurrada, construída também com chapa galvanizada, à qual foi acoplado um cano plástico (PVC) com $100 \mathrm{~mm}$ de diâmetro, com a finalidade de conduzir o escoamento superficial até uma pequena trincheira localizada $6 \mathrm{~m}$ adiante, onde eram, intermitentemente, a cada três minutos, medidas as vazões e coletadas as amostras de enxurrada. Para isso, utilizou-se proveta graduada, cronômetro e potes plásticos de $1 \mathrm{~L}$.

Os tratamentos foram dispostos em delineamento experimental próximo ao completamente casualizado (sortearam-se apenas os pares de parcelas de erosão destinados a cada tratamento), envolvendo tipos de sequência cultural, métodos de preparo do solo e níveis de cobertura por resíduo cultural, conforme especificados a seguir.

- Tratamento 1: quatro anos de uso do solo com a sucessão de culturas aveia-preta (Avena strigosa)milho (Zea mays), seguidos de três anos e meio de uso com a sucessão aveia-preta - milheto
(Pennisetum americanum), ambas em semeadura direta. Doravante este tratamento (de forma análoga também os seguintes) será referido como primeira sequência cultural da lista (das sequências culturais arroladas nos quadros e figuras deste trabalho) ou, alternativamente, $4 \mathrm{Av}-\mathrm{Mi}, \mathrm{SD} / 3,5 \mathrm{Av}-\mathrm{Mt}, \mathrm{SD})$.

- Tratamento 2: quatro anos sem cultivo e sem preparo do solo (com resíduos culturais uniformemente espalhados sobre as parcelas experimentais para proteger a superfície do solo e com controle químico ou mecânico da vegetação espontânea), seguidos de três anos e meio de uso com a sucessão de culturas ervilhaca (Vicia sativa) - feijão miúdo (Vigna unguiculata), em semeadura direta. Doravante este tratamento será referido como segunda sequência cultural da lista ou $4 \mathrm{Sc}, \mathrm{SP} /$ $3,5 \mathrm{Er}-\mathrm{Fm}, \mathrm{SD})$.

- Tratamento 3: sete anos sem cultivo e sem preparo do solo (com manejo igual ao Tratamento 2 ), seguidos de meio ano de uso com a cultura de aveia-preta em semeadura direta. Doravante este tratamento será referido como terceira sequência cultural da lista ou $7 \mathrm{Sc}, \mathrm{SP} / 0,5 \mathrm{Av}, \mathrm{SD})$.

- Tratamento 4: quatro anos de uso do solo com a sucessão de culturas aveia-preta - milho, em semeadura direta, seguidos de três anos e meio sem cultivo e sem preparo do solo (com manejo igual aos dos Tratamentos 2 e 3). Doravante, este tratamento será referido como quarta sequência cultural da lista, ou $4 \mathrm{Av}-\mathrm{Mi}, \mathrm{SD} / 3,5 \mathrm{Sc}, \mathrm{SP})$.

A semeadura das culturas foi efetuada no sentido do declive do terreno, conforme filosofia de obtenção do fator $\mathrm{C}$ - cobertura e manejo do solo dos modelos "USLE" e "RUSLE" de predição da erosão hídrica (Wischmeier \& Smith, 1978; Renard et al., 1997).

Realizaram-se sete testes de erosão com chuva simulada (T1 a T7), cada um na intensidade constante de $63,5 \mathrm{~mm} \mathrm{~h}^{-1}$ e com duração de $1,5 \mathrm{~h}$. O primeiro teste (T1) foi realizado no final de outubro de 2003, logo após a colheita das culturas de inverno (aveiapreta e ervilhaca), com seus resíduos culturais uniformemente espalhados na superfície do solo nas parcelas experimentais e sem nenhum preparo do solo. Assim, neste primeiro teste de chuva (T1), o solo em todas as sequências culturais se encontrava não mobilizado (superfície consolidada e praticamente nenhuma rugosidade) e completamente coberto por resíduos culturais. Onze dias após a realização do teste $\mathrm{T} 1$, os resíduos culturais, na medida do possível, foram todos removidos da superfície do solo nas parcelas experimentais e, em seguida, foi realizado o segundo teste de chuva simulada (T2), também sem nenhum preparo do solo. Dessa forma, neste segundo teste de chuva (T2), o solo em todas as sequências culturais continuava com a sua superfície não mobilizada (consolidada e praticamente sem rugosidade), porém, dessa vez, sem cobertura de 
resíduos culturais. Aos 26, 42, 98, 154 e 172 dias de realização do segundo teste de chuva (T2), foram, respectivamente, realizados o terceiro (T3), o quarto (T4), o quinto (T5), o sexto (T6) e o sétimo (T7) teste, porém, dessas vezes, com o solo em todas as sequências culturais, imediatamente antes da aplicação de cada chuva simulada, tendo sido mobilizado com grade leve (uma operação única em cada teste). Para isso, empregou-se uma grade niveladora (excêntrica) constituída de 36 discos lisos, possuindo $0,54 \mathrm{~m}$ de diâmetro cada um, que operaram no solo na profundidade média de 0,15 m. Assim, nos testes de chuva simulada T3 a T7, o solo em todas as sequências culturais se apresentava com a sua superfície mobilizada (solta e rugosa) e descoberta.

A massa de raízes das últimas culturas inseridas no experimento foi avaliada antes do início dos testes de erosão com chuva simulada, em cada parcela experimental. Para isso, coletaram-se amostras compostas de solo, cada uma constituída de seis subamostras, as quais foram retiradas das camadas de solo de 0 a $0,10 \mathrm{~m}$ e 0,10 a 0,20 m, por meio do uso de um trado de ferro de formato cilíndrico, $\operatorname{com} 3,81 \mathrm{~cm}$ de diâmetro, o que equivaleu ao volume de solo de $173,5 \mathrm{~cm}^{3}$ em cada subamostra. Após a coleta, as amostras de solo foram secas ao ar, em casa de vegetação, por 24 a $72 \mathrm{~h}$, sendo posteriormente leve e manualmente fragmentadas e lavadas sob jato de água de torneira, em peneira com $0,5 \mathrm{~mm}$ de malha. A seguir, as raízes foram transferidas para latas de alumínio e secas em estufa a $60^{\circ} \mathrm{C}$ por $24 \mathrm{~h}$, sendo posteriormente pesadas. Tomando por base o volume de solo amostrado e a massa de raízes contida na amostra, e efetuando-se as devidas conversões de unidades, calculou-se a quantidade total de raízes em cada tratamento, expressa nas unidades de $\mathrm{Mg} \mathrm{ha}^{-1}$.

$\mathrm{O}$ diâmetro médio ponderado (DMP) de agregados do solo foi determinado antes de cada teste de erosão com chuva simulada, em cada parcela experimental, usando-se a técnica de peneiramento do material úmido (Yoder, 1936). Para isso, coletaram-se amostras compostas de solo, cada uma constituída de cinco subamostras retiradas das camadas de solo de 0 a $0,10 \mathrm{~m}$ e 0,10 a $0,20 \mathrm{~m}$ no solo não mobilizado e de 0 a $0,15 \mathrm{~m}$ no solo mobilizado, com o auxílio de uma pequena pá de corte e de uma concha de pedreiro. Os fragmentos de solo ou pequenos torrões que resultavam da retirada das amostras com os equipamentos recémreferidos foram passados, ainda sob a umidade atual de campo, em um conjunto de duas peneiras, com malhas de 7,96 e 4,76 mm, sobrepostas nesta ordem. Os agregados de solo retidos na peneira com malha menor foram acondicionados em potes plásticos, levados para o laboratório e postos a secar ao ar por 48 a 72 h. Após secos, os agregados foram novamente passados na peneira com malha de $4,76 \mathrm{~mm}$, descartando-se a porção que passava por ela. Em prosseguimento, tomaram-se $50 \mathrm{~g}$ da amostra selecionada e colocou-se ela sobre um conjunto de cinco peneiras, com malhas de 4,$76 ; 2 ; 1 ; 0,5$; e $0,25 \mathrm{~mm}$, sobrepostas nesta ordem. Este conjunto de peneiras foi submerso em água por 10 minutos e, em seguida, submetido à oscilação mecânica vertical, também por 10 minutos, na velocidade de 25 oscilações por minuto. A distribuição dos agregados de solo nas classes de tamanho referidas, em base percentual, foi obtida pela razão entre a massa seca $\left(105^{\circ} \mathrm{C}\right)$ dos agregados retidos em cada peneira e a sua massa seca total, utilizada na amostra, com os resultados tendo sido expressos em termos de diâmetro médio ponderado (DMP) de agregados, em $\mathrm{mm}$.

Das mesmas amostras de solo que foram coletadas para a análise de distribuição de tamanho de agregados, retirou-se parte e enviou-a ao Laboratório de Análises de Solo do Departamento de Solos da Faculdade de Agronomia da UFRGS, para avaliação do teor de matéria orgânica e do estado geral de fertilidade do solo, segundo os métodos descritos em Tedesco et al. (1985).

A rugosidade superficial do solo foi avaliada imediatamente antes e após o seu preparo e logo após a realização de cada teste de erosão com chuva simulada, utilizando-se para tal um rugosímetro ou perfilômetro semelhante ao descrito por Burwell et al. (1963). O índice de rugosidade superficial do solo, entretanto, foi calculado pela equação proposta por Cogo et al. (2000), que tem a seguinte forma:

$$
I R=\sqrt{\sum_{i=2}^{n} \frac{h_{i}-h_{i-1}}{n-1}}
$$

em que n é o número de leituras efetuadas com o perfilômetro e $h$ as leituras das elevações e depressões da superfície do solo, em $\mathrm{cm}$.

A velocidade da enxurrada foi medida por meio da contagem, com cronômetro, do tempo gasto por um corante (azul de metileno a $2 \%$ ) para percorrer um segmento de $6 \mathrm{~m}$, demarcado equidistante das extremidades de cada parcela experimental, sendo expressa nas unidades de $\mathrm{m} \mathrm{s}^{-1}$. Esta medição foi efetuada na condição de equilíbrio da enxurrada ou sob taxa de descarga constante.

A distribuição de tamanho dos sedimentos erodidos, transportados na enxurrada associada à erosão hídrica, foi avaliada coletando-se amostras desta última e fazendo-as passar por um conjunto de sete peneiras, com malhas de $2 ; 1 ; 0,5 ; 0,25 ; 0,105 ; 0,053 ;$ e 0,0375 mm, sobrepostas nesta ordem. Posteriormente, os sedimentos retidos em cada peneira foram transferidos, com o auxílio de bisnaga plástica contendo água, para latas de alumínio e secos em estufa a $60{ }^{\circ} \mathrm{C}$ por $48 \mathrm{~h}$, pesados e, então, calculado o índice representativo da distribuição de tamanho dos sedimentos transportados na enxurrada ou $\mathrm{D}_{50}$ (tamanho de sedimentos em que $50 \%$, em base de massa, estão acima e $50 \%$ estão abaixo), conforme descrito e ilustrado em Cogo (1981). Esta avaliação foi efetuada concomitantemente à medição da velocidade da enxurrada, ou seja, também sob taxa de descarga constante desta última ou condição de equilíbrio. 
Os resultados obtidos foram submetidos à análise da variância, empregando-se o teste de comparação de médias de Duncan, no nível de probabilidade $p<0,05$. Para isso, utilizou-se o programa computacional ESTAT (Sistema para Análises Estatísticas, v.2.0), desenvolvido pelo Polo Computacional do Departamento de Ciências Exatas da FCAV/UNESP, Jaboticabal (SP). Foram também efetuadas análises de regressão nos modos linear e não linear, usando-se as variáveis de manejo (índice de rugosidade superficial, diâmetro médio ponderado de agregados do solo) e as variáveis erosão hídrica (velocidade da enxurrada e tamanho de sedimentos erodidos) consideradas no estudo. O modelo matemático usado para correlacionar as variáveis referidas foi escolhido com base naquele que melhor descreveu o fenômeno da erosão em relação à dada variável em particular. O grau de significância dos ajustes dos modelos matemáticos foi baseado na metodologia proposta por Fischer \& Yates (1971). A interpretação final dos dados, entretanto, além da consideração estatística, foi baseada em teorias e conceitos desenvolvidos em estudos de mecânica da erosão hídrica pluvial do solo da literatura especializada.

\section{RESULTADOS E DISCUSSÃO}

No quadro 1 são apresentados os resultados da massa seca das raízes das últimas culturas inseridas no experimento, do teor de matéria orgânica e do diâmetro médio ponderado (DMP) dos agregados do solo, em duas de suas camadas, avaliados antes do seu preparo e da realização dos testes de erosão com chuva simulada, nos tratamentos de sequências culturais estudados. Observa-se que houve diferenças estatisticamente significativas entre as sequências culturais em relação às três variáveis mencionadas nas duas camadas avaliadas do solo. Assim, a primeira sequência cultural da lista (4Av-Mi,SD/3,5Av-Mt,SD), com nenhuma interrupção do cultivo, além de criar boas condições físicas no solo, foi a que resultou em maior quantidade de massa seca de raízes observada no estudo. Já a terceira e a última sequência cultural (respectivamente 7Sc,SP/0,5Av,SD e 4Av-Mi,SD/ $3,5 \mathrm{Sc}, \mathrm{SP})$, ambas com maior tempo de interrupção do cultivo, foram as que apresentaram os menores valores das variáveis em consideração nas duas camadas avaliadas do solo. De fato, a última sequência cultural não apresentava raízes por ocasião da avaliação, sendo esta a razão do valor zero registrado no quadro 1 , tendo em vista ter sido suspendido o cultivo do solo e efetuado o controle de toda e qualquer vegetação espontânea nas suas parcelas experimentais nos últimos três anos e meio de condução da pesquisa. Por sua vez, a segunda sequência cultural da lista (4Sc,SP/3,5ErFm,SD), também com nenhuma interrupção do cultivo no último período da pesquisa, ficou em posição um pouco inferior à da primeira e consideravelmente superior à das duas últimas nas duas camadas avaliadas do solo. Os teores de matéria orgânica e valores do diâmetro médio ponderado (DMP) de agregados do solo foram maiores na camada de 0 a $0,10 \mathrm{~m}$, o que é normal, tendo em vista sua maior quantidade de raízes. Como também observado por Tisdall \& Oades (1982) e Silva \& Mielniczuk (1997), os maiores valores de massa seca de raízes e os maiores teores de matéria orgânica proporcionaram os maiores valores do diâmetro médio ponderado (DMP) dos agregados do solo. Informações mais detalhadas a respeito das sequências culturais relacionadas no quadro 1 no que se refere às suas produções de biomassa (aérea e subterrânea) e aos seus efeitos no solo podem ser encontradas no trabalho de Volk (2006) e Volk \& Cogo (2008).

Na figura 1 são apresentados os resultados do diâmetro médio ponderado (DMP) dos agregados do solo nas suas camadas de 0 a $0,10 \mathrm{~m}$ para o solo não mobilizado associado aos testes de erosão T1 e T2 e de 0 a 0,15 m para o solo sucessivamente mobilizado com grade leve associado aos testes de erosão T3 a T7,

Quadro 1. Massa seca de raízes das últimas culturas inseridas no experimento, teor de matéria orgânica e diâmetro médio ponderado (DMP) dos agregados do solo em duas de suas camadas, avaliados antes do seu preparo e do início dos testes de erosão com chuva simulada, nas sequências culturais estudadas (valores médios de duas repetições por tratamento)

\begin{tabular}{|c|c|c|c|c|c|c|}
\hline \multirow{2}{*}{ Sequência cultural } & \multicolumn{2}{|c|}{ Massa seca de raízes $^{(1)}$} & \multicolumn{2}{|c|}{ Teor de matéria orgânica } & \multicolumn{2}{|c|}{ DMP } \\
\hline & $0-10 \mathrm{~cm}$ & $10-20 \mathrm{~cm}$ & $0-10 \mathrm{~cm}$ & $10-20 \mathrm{~cm}$ & $0-10 \mathrm{~cm}$ & $10-20 \mathrm{~cm}$ \\
\hline & \multicolumn{2}{|c|}{$\longrightarrow \mathrm{Mg} \mathrm{ha}^{-1}$} & \multicolumn{2}{|c|}{$\mathrm{g} \mathrm{kg}^{-1}$} & \multicolumn{2}{|c|}{$-\mathrm{mm}$} \\
\hline 4Av-Mi,SD/3,5Av-Mt,SD & $13,5^{(2)} \mathrm{a}$ & $1,3 \mathrm{a}$ & $30 \mathrm{a}$ & $22 \mathrm{a}$ & $4,06 \mathrm{a}$ & $2,59 \mathrm{a}$ \\
\hline 4Sc,SP/3,5Er-Fm,SD & $8,0^{(3)} \mathrm{b}$ & $0,8 \mathrm{~b}$ & $28 \mathrm{ab}$ & $22 \mathrm{a}$ & $3,94 \mathrm{a}$ & $2,42 \mathrm{a}$ \\
\hline $7 \mathrm{Sc}, \mathrm{SP} / 0,5 \mathrm{Av}, \mathrm{SD}$ & $3,1^{(2)} \mathrm{c}$ & $0,8 \mathrm{~b}$ & $22 \mathrm{~b}$ & $20 \mathrm{a}$ & $2,80 \mathrm{~b}$ & $1,51 \mathrm{~b}$ \\
\hline 4Av-Mi,SD/3,5Sc,SP & $0 \mathrm{~d}$ & $0 \mathrm{c}$ & $22 \mathrm{~b}$ & $20 \mathrm{a}$ & $2,10 \mathrm{~b}$ & $0,88 \mathrm{~b}$ \\
\hline
\end{tabular}

${ }^{(1)}$ Em estufa, a $60{ }^{\circ} \mathrm{C} .{ }^{(2)}$ Dominantemente raízes de aveia-preta. ${ }^{(3)}$ Dominantemente raízes de ervilhaca. Valores nas colunas seguidos da mesma letra não diferem estatisticamente entre si (Duncan, $\mathrm{p}<0,05$ ). 
avaliados antes da aplicação das chuvas simuladas nos tratamentos de sequência cultural estudados. Observa-se que houve diferenças estatisticamente significativas entre as sequências culturais quanto aos valores da variável considerada em todos os testes de chuva, o que, num primeiro momento, pode ser explicado pelos diferentes valores de massa seca de raízes das culturas, em conjunção com os diferentes teores de matéria orgânica na camada mais superficial do solo, em cada sequência cultural (Quadro 1). Continuando a análise dos dados apresentados na figura 1, observa-se que, por ocasião da realização do primeiro teste de erosão com chuva simulada (T1), a primeira e a segunda sequência cultural da lista (respectivamente 4Av-Mi,SD/3,5Av-Mt,SD e 4Sc,SP/ 3,5Er-Fm,SD), por conterem maior teor de matéria orgânica e maior quantidade de massa seca de raízes na camada mais superficial do solo (Quadro 1), foram as que apresentaram os maiores valores do diâmetro médio ponderado (DMP) dos agregados do solo. Do segundo (T2) ao último (T7) teste de chuva, os valores de DMP da segunda sequência cultural foram menores do que os da primeira e maiores do que os das duas últimas (4Av-Mi,SD/3,5SP,SC e 7Sc,SP/0,5Av,SD). Essas duas últimas sequências culturais, por apresentarem menor teor de matéria orgânica e valor mais baixo de massa seca de raízes na camada mais superficial do solo do que as duas primeiras (Quadro 1), foram as que apresentaram os menores valores de DMP em todos os testes de chuva, os quais permaneceram estatisticamente diferentes entre si até o quarto teste (T4).

$\mathrm{Na}$ figura 2 são apresentados os resultados do índice da rugosidade superficial do solo (IR) criada pelo preparo, obtidos em momentos distintos durante o período de realização dos testes de erosão com chuva simulada, nas sequências culturais estudadas. Verifica-se que, antes do preparo do solo (antes da realização dos testes de chuva $\mathrm{T} 1$ e T2), todas as sequências culturais apresentavam valor de IR muito baixo e semelhante entre si, o que é normal. A operação da gradagem, entretanto, efetuada a partir do terceiro teste de chuva (T3), mobilizou o solo com intensidade igual e elevou os valores de IR em todas as sequências culturais, porém, em magnitudes diferentes, provavelmente em função da condição físicoestrutural diferente do solo em cada uma delas (Quadro 1). Assim, a primeira e a segunda sequência cultural da lista (respectivamente 4Av-Mi,SD/3,5Av$\mathrm{Mt}, \mathrm{SD}$ e 4Sc,SP/3,5Er-Fm,SD) tiveram os valores dos seus índices de rugosidade superficial (IR) aumentados pela gradagem, efetuada antes do teste de chuva T3, em cerca de 20 vezes, enquanto a terceira e a última sequência cultural (respectivamente 7Sc,SP/0,5Av,SD e $4 \mathrm{Av}-\mathrm{Mi}, \mathrm{SD} / 3,5 \mathrm{Sc}, \mathrm{SP})$ o tiveram cerca de 12 e 17 vezes, respectivamente. Após a realização do terceiro teste de chuva (T3), a energia erosiva associada a cada chuva simulada aplicada (1.278 MJ mm ha-1 $\mathrm{h}^{-1}$, correspondentes à intensidade constante de $63,5 \mathrm{~mm} \mathrm{~h}^{-1}$ durante 90 minutos) reduziu os valores de IR em cerca de $50 \%$, em todas as sequências culturais, condizendo com o observado por Castro et al. (2006) em estudo semelhante, no mesmo tipo de solo. Contudo, a primeira e a segunda sequência cultural da lista continuaram apresentando valor absoluto do índice IR semelhante entre si e, em média, em torno de duas vezes maior do que os observados na terceira e na última sequência cultural, indicando a maior resistência dos agregados do solo à ação desagregadora do impacto das gotas da chuva. Nos demais testes de chuva (T4 a T7), a primeira sequência cultural da lista (4Av-Mi,SD/3,5Av-Mt,SD)

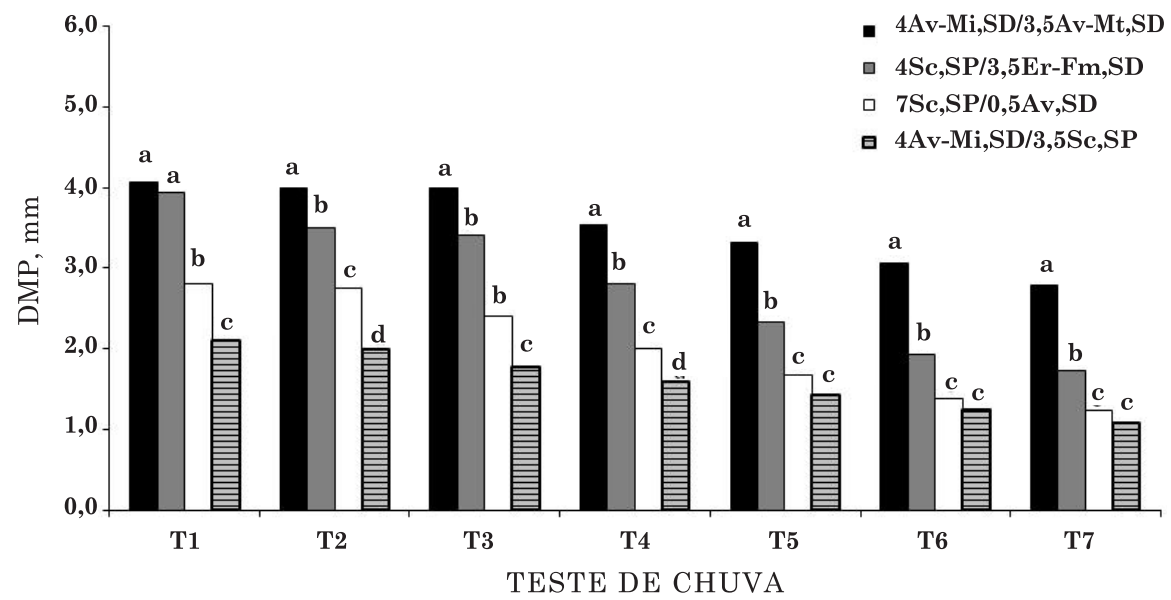

Figura 1. Diâmetro médio ponderado (DMP) dos agregados do solo antes da realização dos testes de erosão com chuva simulada (condição superficial nos testes: $T 1=$ solo não mobilizado e completamente coberto; T2=solo não mobilizado e descoberto; T3 a T7=solo sucessivamente mobilizado com grade leve e descoberto) nas sequências culturais estudadas (valores médios de duas repetições por tratamento). Colunas sobrepostas com a mesma letra, no mesmo teste de chuva, não diferem estatisticamente entre si (Duncan, p < 0,05). 


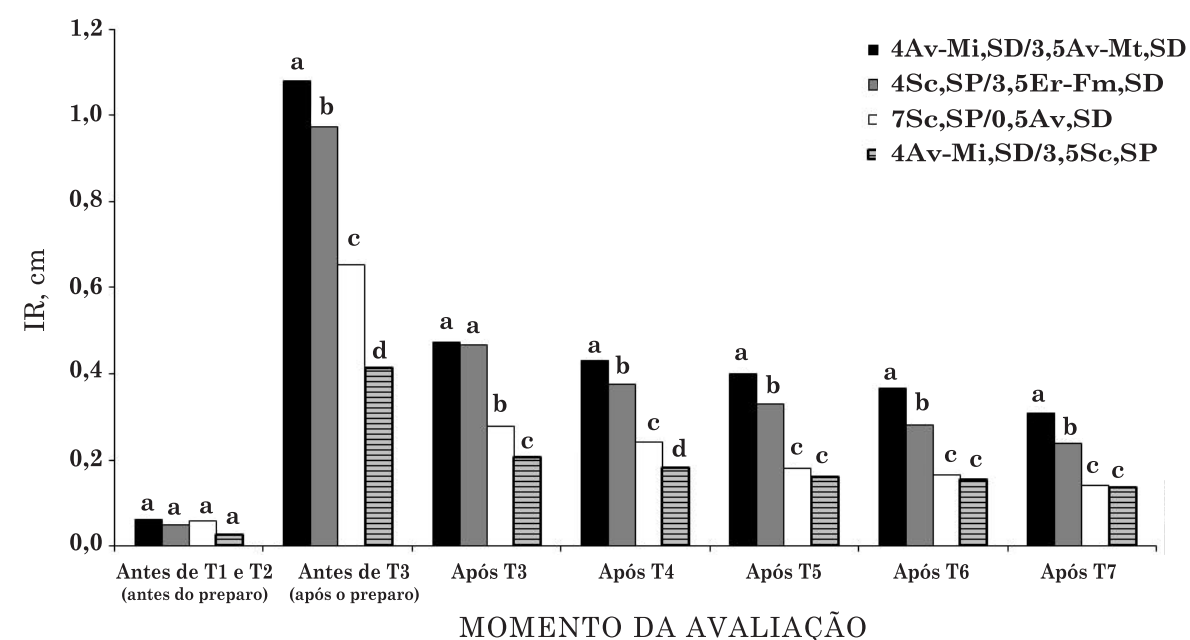

Figura 2. Índice IR da rugosidade superficial do solo criada pelo preparo em momentos distintos durante a realização dos testes de erosão com chuva simulada (condição superficial nos testes: T1=solo não mobilizado e completamente coberto; $\mathrm{T} 2=$ =solo não mobilizado e descoberto; $\mathrm{T} 3 \mathrm{a}$ T7=solo sucessivamente mobilizado com grade leve e descoberto) nas sequências culturais estudadas (valores médios de duas repetições por tratamento). Colunas sobrepostas com a mesma letra, no mesmo teste de chuva, não diferem estatisticamente entre si (Duncan, $p<0,05$ ).

permaneceu com o seu maior valor de IR, seguida de perto pela segunda sequência cultural (4Sc,SP/3,5ErFm,SD). Devido aos pequenos valores de massa seca de raízes e de diâmetro médio ponderado (DMP) de agregados do solo nas mesmas (Quadro 1), a partir do quinto teste de chuva (T5) a terceira e a última sequência cultural da lista (respectivamente 7Sc,SP/ $0,5 \mathrm{Av}, \mathrm{SD}$ e 4Av-Mi,SD/3,5Sc,SP) passaram a exibir os menores valores de IR observados no estudo, sem diferença estatística entre eles.

$\mathrm{Na}$ figura 3 são apresentados os resultados do índice da rugosidade superficial do solo (IR) criada pelo preparo, avaliados logo após a realização de cada teste de erosão com chuva simulada T3 a T7 (solo mobilizado com grade leve e descoberto em todos eles), como função da redução relativa percentual dos valores do diâmetro médio ponderado (DMP) dos agregados do solo, avaliados nas mesmas ocasiões, nos tratamentos de sequência cultural estudados. Esses valores de IR retratam a rugosidade superficial do solo que resistiu à ação erosiva das chuvas simuladas aplicadas. Analisando os dados, observa-se que diminuíram com a redução relativa percentual dos valores de DMP segundo um modelo exponencial, em todas as sequências culturais, com as relações envolvidas tendo sido altamente significativas em todas elas. Assim, pode-se dizer que, quando mobilizado, um solo mais bem estruturado irá apresentar uma superfície bem mais rugosa, e esta maior rugosidade superficial, embora sendo efêmera, irá temporariamente contribuir para maiores retenção e detenção superficiais de água e consequentemente, maior infiltração no solo e, em decorrência, menor perda na forma de enxurrada. Ao mesmo tempo, a rugosidade aumentada da superfície do solo irá induzir a deposição das partículas desagregadas que se encontram sob transporte na enxurrada, resultando em diminuição da perda total de solo por erosão. As relações matemáticas apresentadas na figura 3 ilustram bem a perda da capacidade do solo de resistir ao rebaixamento da sua rugosidade superficial pelas ações de impacto das gotas da chuva e cisalhante da enxurrada, conforme foi diminuindo o tamanho dos seus agregados, como também observado por Bertol et al. (2006).

Os resultados de velocidade da enxurrada, medidos na sua condição de equilíbrio, em cada teste de erosão

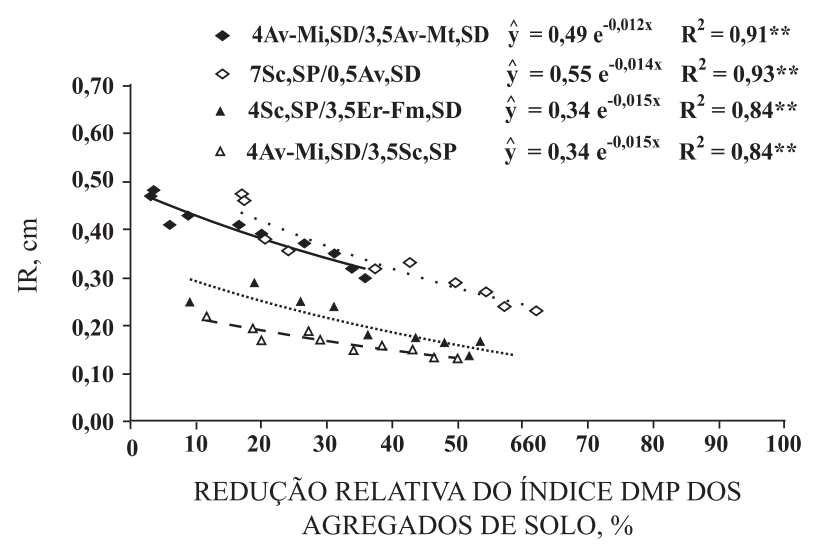

Figura 3. Relação do índice IR da rugosidade superficial do solo criada pelo preparo com a redução relativa percentual (base de massa) do diâmetro médio ponderado (DMP) dos seus agregados nas sequências culturais estudadas (obs.: resultados relativos aos testes de erosão com chuva simulada T3 a T7; em cada um o solo se apresentava mobilizado com grade leve e descoberto). 
com chuva simulada (exceto o teste T1), são apresentados na figura 4 . A razão de não constar o teste T1 nesta figura deve-se ao fato de que não foi possível medir a velocidade da enxurrada com o método empregado, tendo em vista o solo se encontrar com elevada quantidade de resíduos culturais superficiais. Analisando os dados da figura 4, observa-se que houve diferenças significativas entre as sequências culturais quanto à variável em consideração em todos os testes de chuva. Assim, no segundo teste (T2), em que o solo se apresentava não mobilizado (superfície consolidada e praticamente nenhuma rugosidade) e descoberto, visualmente constatou-se, por não ter havido formação de sulcos na superfície do solo das três primeiras sequências culturais da lista $(4 \mathrm{Av}$ $\mathrm{Mi}, \mathrm{SD} / 3,5 \mathrm{Av}-\mathrm{Mt}, \mathrm{SD}, 4 \mathrm{Sc}, \mathrm{SP} / 3,5 \mathrm{Er}-\mathrm{Fm}, \mathrm{SD}$ e $7 \mathrm{Sc}, \mathrm{SP} /$ $0,5 \mathrm{Av}, \mathrm{SD}$ ), que o fluxo superficial de água se deu na forma predominantemente laminar, o que explica os menores valores de velocidade da enxurrada, com superioridade, em igual grau, das duas primeiras, entretanto explicado pela suas maiores taxas de infiltração de água no solo na condição de equilíbrio da enxurrada, conforme dados apresentados em Volk $\&$ Cogo (2008). Por sua vez, embora com a aparente mesma condição física na superfície do solo, a última sequência cultural da lista (4Av-Mi,SD/3,5Sc,SP) permitiu a formação de sulcos na sua parcela experimental e, em decorrência, a enxurrada na mesma escoou com velocidade maior do que nas sequências culturais já mencionadas e, praticamente, no mesmo nível que a dos testes de chuva T4 a T7, quando o solo se apresentava mobilizado, descoberto e com sulcos direcionados no sentido do declive, devido à operação da gradagem. No terceiro teste de chuva (T3), a criação de rugosidade superficial no solo, resultante do seu primeiro preparo com grade leve (Figura 2), determinou os menores valores de velocidade da enxurrada dentre os observados no estudo em qualquer das sequências culturais. No quarto teste de chuva (T4), o índice de rugosidade superficial do solo após o preparo se apresentava menor do que no teste anterior (T3) em todas as sequências culturais (Figura 2), fato que, associado à formação mais intensa de sulcos na superfície do solo nas parcelas experimentais, comparada à verificada no teste T3, determinou valores de velocidade da enxurrada superiores aos deste último. Do quinto (T5) ao sétimo (T7) teste de chuva, apenas a primeira sequência cultural da lista (4Av-Mi,SD/3,5Av-Mt,SD) apresentou valor de velocidade da enxurrada significativamente menor do que o das demais sequências, as quais exibiram valores estatisticamente iguais.

Os diferentes valores do diâmetro médio ponderado (DMP) dos agregados do solo (Figura 1), índice da rugosidade superficial (IR) criada pelo preparo (Figura 2) e velocidade da enxurrada (Figura 4), motivados pelas sequências culturais estudadas, determinaram diferenças no tamanho dos sedimentos transportados na enxurrada (condição de equilíbrio), conforme pode ser observado nos quadros 2 e 3 . Esses resultados serão discutidos separadamente, conforme feito a seguir.

Analisando os dados do quadro 2, com os valores do índice $D_{50}$ dos sedimentos transportados na enxurrada, verifica-se que houve diferenças estatisticamente significativas entre os tratamentos de sequência cultural somente no segundo (T2) e no terceiro (T3) teste de erosão com chuva simulada. No primeiro teste (T1), a cobertura integral do solo com resíduos culturais determinou valores do índice $\mathrm{D}_{50}$ muito baixos em todas as sequências culturais, indicando que a enxurrada transportou sedimentos dominantemente do tamanho das frações silte e argila.

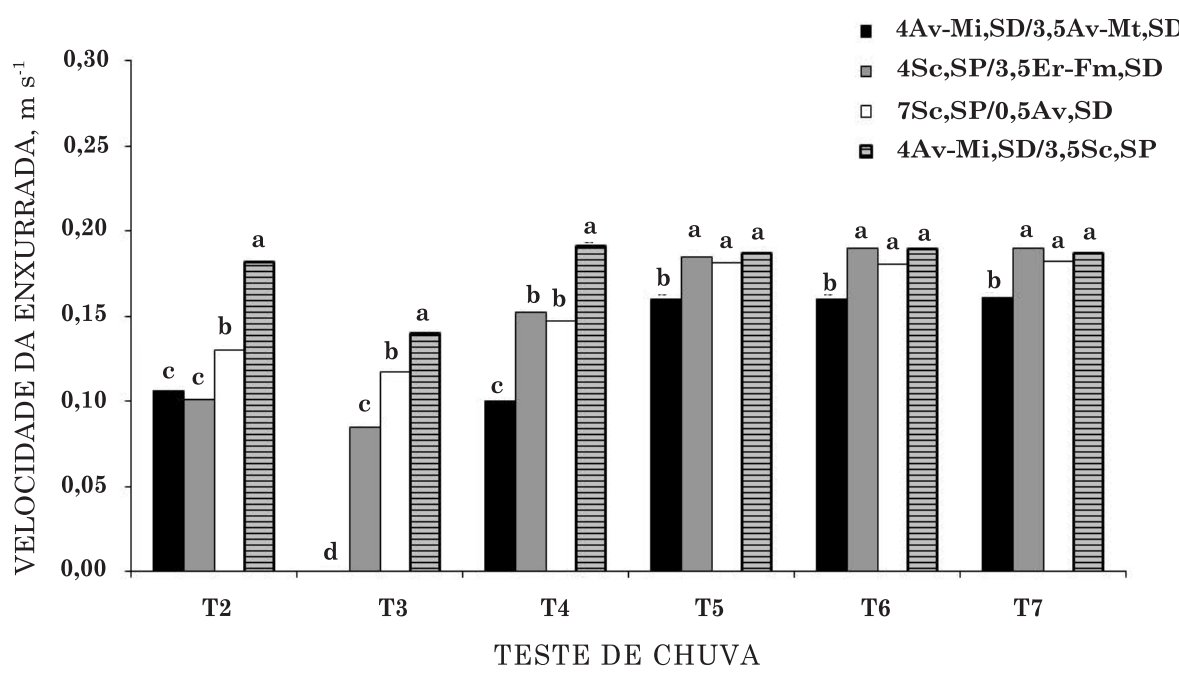

Figura 4. Velocidade da enxurrada na sua condição de equilíbrio, nos testes de erosão com chuva simulada (condição superficial nos testes: $\mathrm{T} 1=$ solo não mobilizado e completamente coberto; $T 2=$ solo não mobilizado e descoberto; $\mathrm{T} 3$ a $\mathrm{T} 7=$ solo sucessivamente mobilizado com grade leve e descoberto) nas sequências culturais estudadas (valores médios de duas repetições por tratamento). Colunas sobrepostas com a mesma letra, no mesmo teste de chuva, não diferem estatisticamente entre si (Duncan, p < 0,05). 
No segundo teste de chuva (T2), a primeira e a segunda sequência cultural da lista (respectivamente $4 \mathrm{Av}$ $\mathrm{Mi}, \mathrm{SD} / 3,5 \mathrm{Av}-\mathrm{Mt}, \mathrm{SD}$ e $4 \mathrm{Sc}, \mathrm{SP} / 3,5 \mathrm{Er}-\mathrm{Fm}, \mathrm{SD})$ apresentaram valores do índice $\mathrm{D}_{50}$ bem menores do que os da terceira e da última (respectivamente $7 \mathrm{Sc}, \mathrm{SP} /$ $0,5 \mathrm{Av}, \mathrm{SD}$ e $4 \mathrm{Av}-\mathrm{Mi}, \mathrm{SD} / 3,5 \mathrm{Sc}, \mathrm{SP})$, mesmo todas elas tendo apresentado valores estatisticamente semelhantes do índice da rugosidade superficial do solo (IR) criada pelo preparo (Figura 2). Isto pode ser explicado pela menor velocidade da enxurrada (Figura 4) e maior estabilidade estrutural do solo (deduzida dos maiores valores de DMP - Figura 1) nas duas primeiras sequências culturais. No terceiro teste de chuva (T3), as condições físicas externas ou superficiais do solo, resultantes do seu preparo com grade, causaram redução no valor do índice $\mathrm{D}_{50}$ apenas na primeira sequência cultural $(4 \mathrm{Av}-\mathrm{Mi}, \mathrm{SD} / 3,5 \mathrm{Av}$ $\mathrm{Mt}, \mathrm{SD}$ ). Provavelmente, isso se deveu ao fato de que esta sequência cultural foi a que apresentou maiores valores tanto do índice DMP dos agregados do solo (Figura 1) quanto do índice IR da sua rugosidade superficial criada pelo preparo (Figura 2), o que, em princípio, conferiu maior resistência à superfície do solo contra a ação desagregadora de suas partículas pelas forças da chuva e da enxurrada a ela associada. Nos demais testes de chuva (T4 a T7), os valores do índice $\mathrm{D}_{50}$ foram relativamente grandes e semelhantes entre si em todas as sequências culturais, o que era esperado tendo em vista a diminuição do efeito residual (benéfico) das sequências culturais na estrutura do solo, causada pela sua mobilização sucessiva com grade leve e pela ação repetida das chuvas simuladas aplicadas.

No que se refere aos sedimentos transportados na enxurrada (condição de equilíbrio) com tamanho $<0,0375 \mathrm{~mm}$ (dominantemente frações de silte $\mathrm{e}$ argila), os dados obtidos são apresentados no quadro 3. Analisando esses dados, verifica-se que a ausência de preparo e a cobertura integral do solo com resíduos culturais, por ocasião da realização do primeiro teste erosão com chuva simulada (T1), como já discutido na análise dos dados do índice $\mathrm{D}_{50}$, permitiram o transporte de sedimentos exclusivamente de tamanho $<0,0375 \mathrm{~mm}$ em todas as sequências culturais. No segundo teste de chuva (T2), no qual o solo ainda se apresentava não mobilizado, porém tendo sido retirada a sua cobertura por resíduos culturais, a maior estabilidade estrutural do solo na primeira sequência cultural (4Av-Mi,SD/3,5Av-Mt,SD), pressuposta pelo seu maior valor de DMP (Figura 1), fez com que a maior parte das partículas desagregadas transportadas na enxurrada fosse pequena (Quadro 2), o que aumentou o percentual dos sedimentos com tamanho $<0,0375 \mathrm{~mm}$, comparado ao dos demais tratamentos. Nos testes subsequentes (T3 a T7), nos quais o solo se apresentava mobilizado com grade leve e descoberto, o percentual dos sedimentos transportados na enxurrada com tamanho $<0,0375 \mathrm{~mm}$ continuou sendo significativamente diferente entre as sequências culturais e diminuiu na ordem de realização dos testes de chuva em todos tratamentos.

O efeito da rugosidade superficial do solo criada pelo preparo na redução da velocidade da enxurrada pode ser visto na figura $5 \mathrm{a}$, enquanto que no transporte dos sedimentos erodidos com tamanho $<0,0375 \mathrm{~mm}$ na figura $5 \mathrm{~b}$. Chama-se a atenção para o fato de que os valores de velocidade da enxurrada e do percentual de sedimentos transportados na mesma com tamanho $<0,0375 \mathrm{~mm}$, associados ao primeiro teste de erosão com chuva simulada (T1), não estão incluídos nas relações apresentadas nas figuras referidas. Isso se deveu à cobertura integral do solo com resíduos culturais naquele teste, o que impossibilitou a medição da velocidade da enxurrada com o método empregado, ao mesmo tempo em que, também, foram os resíduos culturais e não a rugosidade superficial o fator determinante do tamanho dos sedimentos transportados na enxurrada. Assim, observa-se na figura 5a que a velocidade da enxurrada apresentou relação linear descendente com o índice da rugosidade superficial do solo (IR) criada pelo preparo, indicando que quanto maior o valor deste último tanto menor o valor da

Quadro 2. Índice $\mathrm{D}_{50}$ da distribuição de tamanho dos sedimentos erodidos na condição de equilíbrio da enxurrada nos testes de erosão com chuva simulada (condição superficial nos testes: T1=solo não mobilizado e completamente coberto; $\mathrm{T} 2=$ =solo não mobilizado e descoberto; $\mathrm{T} 3$ a $\mathrm{T} 7=$ =solo sucessivamente mobilizado com grade leve e descoberto), nas sequências culturais estudadas (valores médios de duas repetições por tratamento)

\begin{tabular}{|c|c|c|c|c|c|c|c|}
\hline \multirow{2}{*}{ Sequência cultural } & \multicolumn{7}{|c|}{ Índice $\mathrm{D}_{50}$} \\
\hline & $\mathrm{T} 1^{(1)}$ & $\mathrm{T} 2^{(2)}$ & $\mathbf{T} 3^{(3)}$ & $\mathbf{T} 4^{(3)}$ & $\mathbf{T} 5^{(3)}$ & $\mathrm{T} 6^{(3)}$ & $\mathrm{T} 7^{(3)}$ \\
\hline & & & & $-\mathrm{mm}-$ & 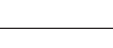 & 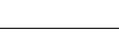 & - \\
\hline 4Av-Mi,SD/3,5Av-Mt,SD & $<0,0375 \mathrm{a}$ & $0,048 \mathrm{~b}$ & $0,296 \mathrm{~b}$ & $0,402 \mathrm{a}$ & 0,359 a & $0,526 \mathrm{a}$ & $0,431 \mathrm{a}$ \\
\hline $4 \mathrm{Sc}, \mathrm{SP} / 3,5 \mathrm{Er}-\mathrm{Fm}, \mathrm{SD}$ & $<0,0375 \mathrm{a}$ & $0,039 \mathrm{~b}$ & $0,425 \mathrm{a}$ & $0,466 \mathrm{a}$ & $0,424 \mathrm{a}$ & $0,453 \mathrm{a}$ & $0,455 \mathrm{a}$ \\
\hline 7Sc,SP/0,5Av,SD & $<0,0375 \mathrm{a}$ & $0,465 \mathrm{a}$ & $0,597 \mathrm{a}$ & $0,389 \mathrm{a}$ & 0,438 a & 0,518 a & $0,552 \mathrm{a}$ \\
\hline 4Av-Mi,SD/3,5Sc,SP & $<0,0375 \mathrm{a}$ & $0,472 \mathrm{a}$ & $0,548 \mathrm{a}$ & $0,475 \mathrm{a}$ & $0,520 \mathrm{a}$ & $0,471 \mathrm{a}$ & $0,480 \mathrm{a}$ \\
\hline
\end{tabular}

Condição superficial: ${ }^{(1)}$ Solo não mobilizado e completamente coberto. ${ }^{(2)}$ Solo não mobilizado e descoberto. ${ }^{(3)}$ Solo mobilizado e descoberto. Valores nas colunas seguidos da mesma letra não diferem estatisticamente entre si (Duncan, $\mathrm{p}<0,05)$. 
Quadro 3. Percentual (base de massa) dos sedimentos erodidos com tamanho $<0,0375$ mm, avaliado na condição de equilíbrio enxurrada, nos testes de erosão com chuva simulada, nas sequências culturais estudadas (valores médios de duas repetições por tratamento)

\begin{tabular}{|c|c|c|c|c|c|c|c|}
\hline \multirow{2}{*}{ Sequência cultural } & \multicolumn{7}{|c|}{ Sedimentos $<0,0375 \mathrm{~mm}$} \\
\hline & $\mathrm{T} 1^{(1)}$ & $\mathrm{T} 2{ }^{(2)}$ & $\mathbf{T} 3^{(3)}$ & $\mathbf{T} 4^{(3)}$ & $\mathbf{T} 5^{(3)}$ & $\mathrm{T} 6^{(3)}$ & $\mathrm{T}^{(3)}$ \\
\hline & & & & $\%$ & & & - \\
\hline 4Av-Mi,SD/3,5Av-Mt,SD & $100 \mathrm{a}$ & $20,7 \mathrm{a}$ & $19,4 \mathrm{a}$ & $19,8 \mathrm{a}$ & $17,4 \mathrm{a}$ & $10,0 \mathrm{a}$ & $7,9 \mathrm{a}$ \\
\hline $4 \mathrm{Sc}, \mathrm{SP} / 3,5 \mathrm{Er}-\mathrm{Fm}, \mathrm{SD}$ & $100 \mathrm{a}$ & $12,5 \mathrm{~b}$ & $16,2 \mathrm{~b}$ & $6,7 \mathrm{~b}$ & $6,5 \mathrm{~b}$ & $7,5 \mathrm{ab}$ & $7,9 \mathrm{a}$ \\
\hline $7 \mathrm{Sc}, \mathrm{SP} / 0,5 \mathrm{Av}, \mathrm{SD}$ & $100 \mathrm{a}$ & $8,3 \mathrm{c}$ & $3,5 \mathrm{~d}$ & $6,3 \mathrm{~b}$ & $6,3 \mathrm{~b}$ & $4,3 \mathrm{~b}$ & $3,7 \mathrm{~b}$ \\
\hline 4Av-Mi,SD/3,5Sc,SP & $100 \mathrm{a}$ & $5,5 \mathrm{~d}$ & $7,5 \mathrm{c}$ & $3,2 \mathrm{c}$ & $3,2 \mathrm{c}$ & $3,2 \mathrm{c}$ & $3,0 \mathrm{~b}$ \\
\hline
\end{tabular}

Condição superficial: ${ }^{(1)}$ Solo não mobilizado e completamente coberto. ${ }^{(2)}$ Solo não mobilizado e descoberto. ${ }^{(3)}$ Solo mobilizado e descoberto. Valores nas colunas seguidos da mesma letra não diferem estatisticamente entre si (Duncan, $p<0,05)$.

primeira, o que irá se refletir em menor capacidade erosiva da mesma para desagregar e transportar solo. Em relação ao percentual dos sedimentos transportados na enxurrada com tamanho $<0,0375 \mathrm{~mm}$, observa-se na figura $5 \mathrm{~b}$ que apresentou relação exponencial crescente com o índice IR, medido logo após a aplicação dos testes de erosão com chuva simulada, evidenciando que, com o aumento da rugosidade superficial do solo, os sedimentos menores ficam retidos nas microdepressões ou microcavidades
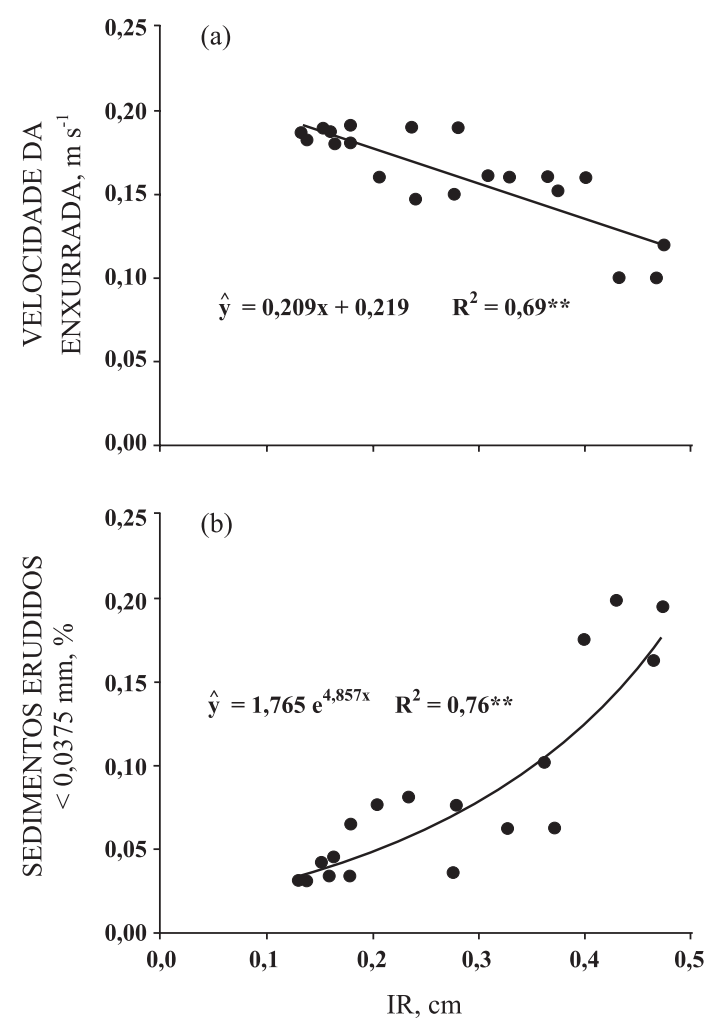

Figura 5. Relação da velocidade da enxurrada (a) e do percentual (base de massa) dos sedimentos erodidos com tamanho $<0,0375 \mathrm{~mm}(\mathrm{~b})$, ambos avaliados na condição de equilíbrio da enxurrada, com o índice IR da rugosidade superficial do solo criada pelo preparo. originadas, e, dessa forma, são transportados para fora da área de ocorrência do fenômeno apenas os sedimentos pequenos. Verifica-se ainda nas figura $5 \mathrm{a}, \mathrm{b}$ que ambos os modelos matemáticos se ajustaram significativamente aos resultados.

$\mathrm{Na}$ figura 6 é apresentada a relação entre o percentual dos sedimentos transportados na enxurrada (condição de equilíbrio) com tamanho $<0,0375 \mathrm{~mm}$ e o diâmetro médio ponderado (DMP) dos agregados do solo. Igualmente como se procedeu na construção das figura $5 a, b$ e pelo mesmo motivo (cobertura integral do solo com resíduos culturais), não estão incluídos na relação apresentada na figura 6 os valores das variáveis em consideração associados ao primeiro teste de erosão com chuva simulada (T1). Observa-se, na referida figura, que a relação entre os sedimentos transportados na enxurrada com tamanho $<0,0375 \mathrm{~mm}$ e o diâmetro médio ponderado (DMP) dos agregados do solo foi exponencial crescente, com o modelo matemático usado na inter-relação tendo apresentado grau de ajuste significativo aos resultados. Dessa forma, pode-se dizer que o tamanho aumentado dos agregados do solo (pressupõe-se aumento também

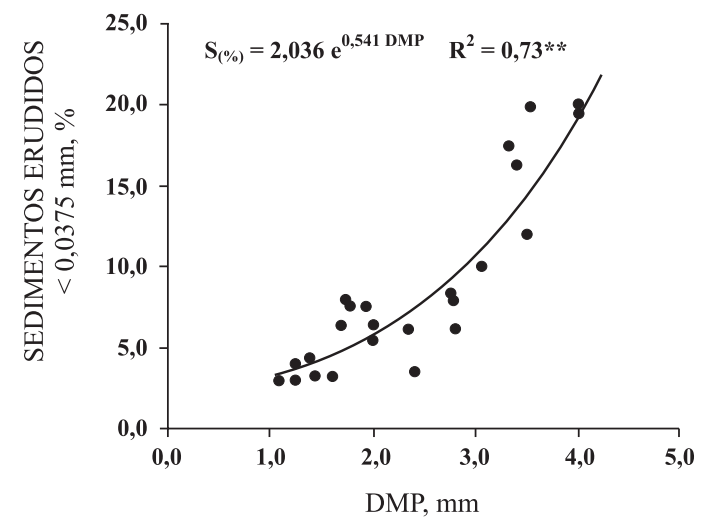

Figura 6. Relação do percentual (base de massa) dos sedimentos erodidos com tamanho $<0,0375 \mathrm{~mm}$, avaliado na condição de equilíbrio enxurrada, com o diâmetro médio ponderado (DMP) dos agregados do solo. 
da sua estabilidade) resultou em maior resistência da sua superfície à ação desagregadora de suas partículas pelo impacto das gotas da chuva e pela ação cisalhante da enxurrada, fazendo com que esta última transportasse apenas sedimentos menores que se encontravam prontamente disponíveis para o transporte.

\section{CONCLUSÕES}

1. As sequências culturais proporcionaram valores da matéria seca de raízes das espécies vegetais que as constituíram significativamente diferentes entre si, o que se refletiu em valores significativamente diferentes do teor de matéria orgânica e do diâmetro médio ponderado (DMP) dos agregados do solo, com as sequências com nenhum ou menos tempo de supressão do cultivo tendo produzido os melhores resultados.

2. Os valores significativamente diferentes do diâmetro médio ponderado (DMP) dos agregados do solo induziram valores significativamente diferentes do índice IR da rugosidade superficial do solo criada pelo preparo e, em decorrência, da velocidade da enxurrada e do índice $\mathrm{D}_{50}$ da distribuição de tamanho dos sedimentos erodidos.

3. A cobertura do solo por resíduos culturais foi a principal responsável pela diminuição, tanto da velocidade da enxurrada, quanto do tamanho dos sedimentos erodidos na condição de solo não-mobilizado e totalmente coberto, enquanto a consolidação da superfície do solo e o diâmetro médio ponderado (DMP) dos seus agregados foram os principais responsáveis pelo último efeito referido na condição de solo nãomobilizado e descoberto, na qual a enxurrada atingiu as suas maiores velocidades.

4. A rugosidade superficial do solo criada pelo preparo foi a principal responsável pela diminuição, tanto da velocidade da enxurrada, quanto do tamanho dos sedimentos erodidos na condição de solo sucessivamente mobilizado com grade leve e descoberto, independentemente do diâmetro médio ponderado (DMP) dos agregados do solo.

5. O aumento do diâmetro médio ponderado (DMP) dos agregados do solo acarretou maior valor e maior persistência da rugosidade superficial criada pelo preparo.

6. As relações matemáticas efetuadas com as variáveis em consideração indicaram tendência de ajustes significativos a modelos linear e não-linear e foram coerentes na descrição dos processos que se pretendia visualizar com a realização da pesquisa.

\section{LITERATURA CITADA}

ALBUQUERQUE, J.A.; CASSOL, E.A. \& REINERT, D.J. Relação entre a erodibilidade em entressulcos e estabilidade dos agregados. R. Bras. Ci. Solo, 24:141-151, 2000.
BERTOL, I.; AMARAL, A.J.; VAZQUEZ, E.V.; GONZALEZ, A.P.; BARBOSA, F.T. \& BRIGNONI, L.F. Relações da rugosidade superficial do solo com o volume de chuva e com a estabilidade de agregados em água. R. Bras. Ci. Solo, 30:543-553, 2006.

BURWELL, R.E.; ALLMARAS, R.R. \& AMEMIYA, M. A field measurement of total porosity and surface microrelief of soils. Soil Sci. Soc. Am. Proc., 27:696-700, 1963.

CASTRO, L.G.; COGO, N.P. \& VOLK, L.B.S. Alterações na rugosidade superficial do solo pelo preparo e pela chuva e sua relação com a erosão hídrica. R. Bras. Ci. Solo, 30:339352, 2006.

COGO, N.P.; CASTRO, L.G. \& van LIER, Q.J. Índices de rugosidade superficial e sua correlação com perdas de solo. In: REUNIÃO BRASILEIRA DE MANEJO E CONSERVAÇÃO DO SOLO E DE ÁGUA, 13., Ilhéus, 2000. Anais.Viçosa, MG, Sociedade Brasileira de Ciência do Solo, 2000. CD ROM.

COGO, N.P.; MOLDENHAUER, W.C. \& FOSTER, G.R. Effect of residue cover, tillage-induced roughness, and runoff velocity on size distribution of eroded soil aggregates. Soil Sci. Soc. Am. J., 47:1005-1008, 1983.

COGO, N.P.; MOLDENHAUER, W.C. \& FOSTER, G.R. Soil loss reductions from conservation tillage practices as expressed by a mulch factor. Soil Sci. Soc. Am. J., 48:368373, 1984.

COGO, N.P. Effect of residue cover, tillage induce roughness, and slope lenght on erosion and related parameters. West Lafayette, Purdue University, 1981. 346p. (Tese de Doutorado)

EMPRESA BRASILEIRA DE PESQUISA AGROPECUÁRIA AEMBRAPA. Recomendações gerais do encontro sobre o uso do simulador de chuva em pesquisa de conservação do solo no Brasil. In: ENCONTRO NACIONAL SOBRE PESQUISA DE EROSÃO COM SIMULADOR DE CHUVA. Londrina, 1975. Resumos. Londrina, IAPAR, 1975. p.107-120.

EMPRESA BRASILEIRA DE PESQUISA AGROPECUÁRIA AEMBRAPA. Sistema brasileiro de classificação de solos. 2.ed. Rio de Janeiro, Centro Nacional de Pesquisa de Solos, 2006. 412p.

FISHER, R.A. \& YATES, F. Tabelas estatísticas para biologia, medicina e agricultura. São Paulo, EDUSP, 1971. 150p.

GILLEY, J.E.; FINKNER, S.C.; SPOMER, R.G. \& MIELKE, L.N. Size distribution of sediment as affected by corn residue. Trans. Am. Soc. Agron. Eng., 29:1273-1277, 1986.

HUDSON, N.W. Soil conservation. 3.ed. Ames, Iowa State University Press, 1995. 391p.

JOHNSON, C.B.; MANNERING, J.V. \& MOLDENHAUER, W.C. Influence of surface roughness and clod size and stability on soil and water losses. Soil Sci. Soc. Am. J., 43:772-777, 1979.

LE BISSONNAIS, Y. \& ARROUYAS, D. Aggregate stability and erodibility: II. Application to humic loamy soils with various organic carbon contents. Eur. J. Soil Sci., 48:3949, 1997. 
LOPES, P.R.C.; COGO, N.P. \& CASSOL, E.A. Influência da cobertura vegetal morta na redução da velocidade da enxurrada e na distribuição de tamanho dos sedimentos transportados. R. Bras. Ci. Solo, 11:193-197, 1987.

MUTCHLER, C.K. \& MURPHREE JR., C.E. Tillage effects on erosion and sediment sizes. Trans. Am. Soc. Agron. Eng., 31:402-407, 1988.

NORTON, L.D.; COGO, N.P. \& MOLDENHAUER, W.C. Effectiveness of mulch in controlling soil erosion. In: ELSWAIFY S.A.; MOLDENHAUER, W.C. \& LO, A., orgs. Soil erosion and conservation. Ankeny, Soil Conservation Society of America, 1985. v.1. p.598-606.

RENARD, K.G.; FOSTER, G.R.; WEESIES, G.A.; McCOOL, D.K. \& YODER, D.C. Predicting soil erosion by water: A guide conservation planning with the revised universal soil loss equation (RUSLE). Washington, USDA, 1997. (Agriculture Handbook, 8)

SHAINBERG, I.; WARRINGTON, D. \& LAFLEN, J.M. Soil dispersibility, rain properties, and slope interaction in rill formation and erosion. Soil Sci. Soc. Am. J., 56:278-283, 1992.

SIDIRAS, N.; ROTH, C.H. \& FARIAS, G.S. Efeito da intensidade de chuva na desagregação por impacto de gotas em três sistemas de preparo do solo. R. Bras. Ci. Solo, 8:251-254, 1984.

SILVA, I.F. \& MIELNICZUK, J. Ação do sistema radicular de plantas na formação e estabilização de agregados de solo. R. Bras. Ci. Solo., 21:113-117, 1997.
STRECK, E.V.; KÂMPF, N. \& KLAMT, E. Atualização da classificação taxonômica das unidades de mapeamento do levantamento de reconhecimento dos solos do Estado do Rio Grande do Sul. Inf. Emater/RS. Série: Solos, 16:15, 1999 .

SWANSON, N.P. A rotating-boom rainfall simulator. Trans. Am. Soc. Agron. Eng., 26:1738-1743. 1965

TISDALL, J.M. \& OADES, J.M. Organic matter and waterstable aggregates in soil. J. Soil Sci., 33:141-163, 1982.

TEDESCO, M.J.; VOLKWEISS, S.J. \& BOHNEN, H. Análises do solo, plantas e outros materiais. Porto Alegre, Universidade Federal do Rio Grande do Sul, 1985. 180p.

VOLK, L.B.S. Condições físicas da camada superficial do solo resultantes do seu manejo e indicadores de qualidade para redução da erosão hídrica e do escoamento superficial. Porto Alegre, Universidade Federal do Rio Grande do Sul, 2006. 148p. (Tese de Doutorado)

VOLK, L.B.S. \& COGO, N.P. Inter-relação biomassa vegetal subterrânea-estabilidade de agregados-erosão hídrica em solo submetido a diferentes formas de manejo. R. Bras. Ci. Solo, 32:1713-1722, 2008.

WISCHMEIER, W.H. \& SMITH, D.D. Predicting rainfall erosion losses a guide to conservation planning. Washington, USDA, 1978. 58p. (Handbook, 537)

YODER, R.E. A direct method of aggregate analysis of soils and a study of physical nature of erosion losses. J. Am. Soc. Agron., 28:337-351, 1936. 